See discussions, stats, and author profiles for this publication at: https://www.researchgate.net/publication/41056961

\title{
Molecular identification of the parasites causing cutaneous Leishmaniasis on the Caribbean coast of Colombia
}

Article in Parasitology Research · February 2010

DOI: 10.1007/500436-009-1712-6. Source: PubMed

\section{CITATIONS}

33

5 authors, including:

Juan Alberto Rebollo

Universidad de Cartagena

29 PUBLICATIONS 70 CITATIONS

SEE PROFILE

S. S. Cochero

Universidad de Sucre

22 PUBLICATIONS 83 CITATIONS

SEE PROFILE

Some of the authors of this publication are also working on these related projects:

Project Virtual Screening View project

Project Leishmania in the Caribbean Coast of Colombia View project
Arturo Luna

The University of Tennessee Health Science Center

30 PUBLICATIONS 125 CITATIONS

SEE PROFILE 


\title{
Molecular identification of the parasites causing cutaneous leishmaniasis on the Caribbean coast of Colombia
}

\author{
Lily Paola Martínez • Juan Alberto Rebollo • \\ Arturo Luis Luna $\cdot$ Suljey Cochero • \\ Eduar Elías Bejarano
}

Received: 4 June 2009 / Accepted: 17 December 2009/Published online: 19 January 2010

(C) Springer-Verlag 2010

\begin{abstract}
All clinical manifestations of leishmaniasis exist in Colombia, the cutaneous form being the most frequent in the department of Sucre, where the Leishmania species associated with cutaneous leishmaniasis (CL) is unknown. This study was carried out to determine which Leishmania species was responsible for $\mathrm{CL}$ in Sucre, based on amplification and sequencing of the $C y t b$ gene. Isolates of Leishmania were obtained after CL diagnosis of eight patients who received attention in several health care centers of the study area. The nucleotide sequences obtained from patients were compared to Leishmania reference strains and six of the isolates identified as Leishmania (Viannia) braziliensis, the remaining two being identified as Leishmania (Viannia) panamensis and Leishmania (Viannia) guyanensis. This represents the first report of the presence of $L$. (V.) guyanensis on the Caribbean coast of Colombia.
\end{abstract}

\section{Introduction}

Leishmaniasis is a disease caused by a broad species of the genus Leishmania. To date, 21 species have been reported to cause human infection (Herwaldt 1999). All clinical manifestations of leishmaniasis are present in Colombia, distributed throughout the country, with the cutaneous form

L. P. Martínez · J. A. Rebollo · A. L. Luna • E. E. Bejarano $(\bowtie)$ Grupo de Investigaciones Biomédicas, Universidad de Sucre, Cra. 14 No. 16B-32, A.A. 406, Sincelejo, Colombia

e-mail: eduarelias@yahoo.com

S. Cochero

Departamento Administrativo de Seguridad Social en Salud de Sucre (DASSSALUD),

Cra. 14 No. 15A-140, Sincelejo, Colombia (cutaneous leishmaniasis, CL) responsible for approximately 99\% of cases (Zambrano 2006).

The geographical distribution and frequency of the etiological agents of CL in Colombia have been reviewed previously. Thus, Leishmania (Viannia) panamensis is known to cause $54-80 \%$ of CL cases, predominantly in Northern and Southwestern Colombia, while Leishmania (Viannia) braziliensis is responsible for $10-30 \%$ of cases and is distributed throughout the country. A third species, Leishmania (Viannia) guyanensis is involved in $1-2 \%$ of cases and is mainly present in the Amazon basin, although it was also recently detected in the department of Tolima. Finally, $1-5 \%$ of cases of Leishmania (Leishmania) mexicana infects have only been reported from the departments of Antioquia, Caldas, Nariño, Putumayo, and Santander (Sierra et al. 2006; Saravia et al. 2002; Ovalle et al. 2006; Rodríguez-Barraquer et al. 2008).

The department of Sucre on the Caribbean coast of Colombia presents a remarkable incidence of CL, with 206 cases of the disease diagnosed in 2008 (DASSSALUD, unpublished observations). Although $\mathrm{CL}$ is considered to have been endemic to Sucre since at least the 1980s, the identity of the parasite responsible remains unknown. Identification of the Leishmania species involved has both clinical and epidemiological relevance since it would allow improvement of both control and treatment of the disease, the latter through the provision of an appropriate therapeutic schedule. Studies have shown that the response of patients to treatment varies according to the parasite species responsible for infection (Rodríguez et al. 1994).

Traditionally, both Leishmania taxonomy and species typing have been based on the use of multilocus enzyme electrophoresis (MLEE) (Rioux et al. 1990) and monoclonal antibodies, respectively. However, accurate discrimination of each species is sometimes limited by interspecific phenotypic 


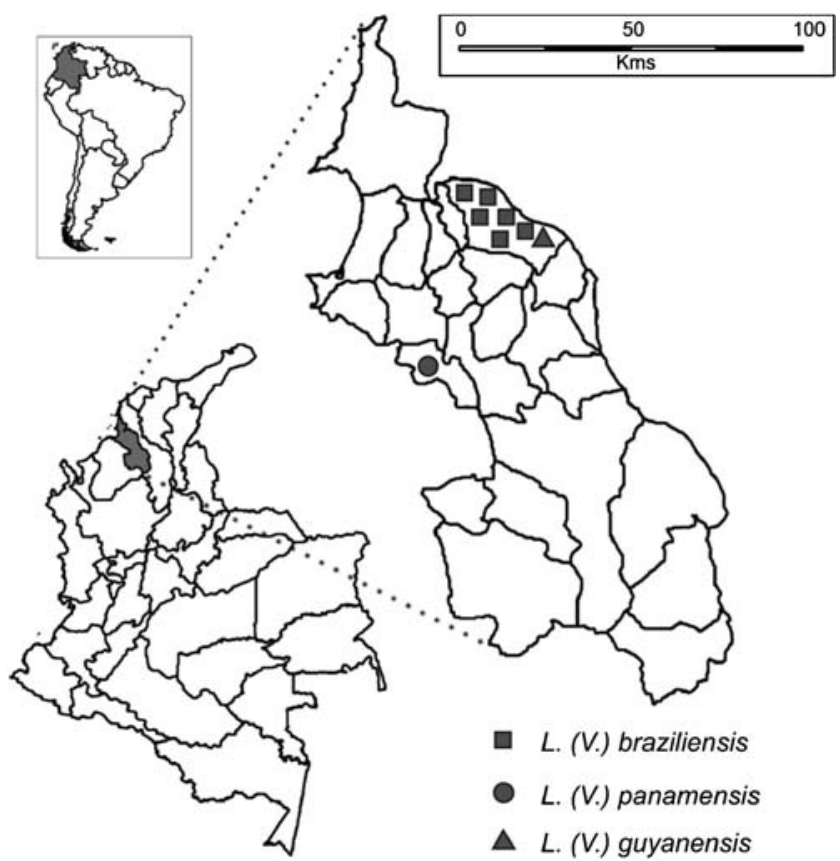

Fig. 1 Distribution of Leishmania clinical isolates identified in the department of Sucre

variation (Bañuls et al. 2007). In recent years, sequencing of the Cytochrome $b(C y t b)$ gene has begun to be used in identification and phylogenetic analyses of wild-type Leishmania isolates (Luyo-Acero et al. 2004; Kato et al. 2005; Marco et al. 2006; Foulet et al. 2007). In this paper, we report the identification of Leishmania species causing $\mathrm{CL}$ in Sucre using $C y t b$ nucleotide sequences and the presence of $L$. (V.) guyanensis on the Colombian Caribbean coast.

\section{Materials and methods}

Collection of samples Eight clinical isolates from patients attended in health care centers of the department of Sucre were included in this study (Fig. 1). Dermal scraping of the lesion edge with a sterile scalpel was performed on six patients from the municipality of Ovejas. Each isolate was placed in $1.5 \mathrm{~mL}$ vials containing $500 \mu \mathrm{L}$ TES buffer (Tris$\mathrm{HCl} 10 \mathrm{mM}$, EDTA $10 \mathrm{mM}$, SDS $0.1 \%$ ) for DNA extraction. In addition, thin-needle aspirative biopsies were carried out after application of a local anesthetic (2\% lidocaine) on two patients, one each from the municipalities of Ovejas and Sampues, was carried out. These latter two samples were placed in tubes containing NNN culture medium for parasite isolation. Four WHO Leishmania reference strains, Leishmania (Leishmania) infantum (MHOM/FR/91/LEM2259), L. (L.) mexicana (MHOM/ MX/95/NAN1), L. (V.) braziliensis (MHOM/CO/88/ $\mathrm{UA301}$ ), and L. (V.) panamensis (MHOM/CO/87/UA140) were included in this study.

Before taking clinical samples, written informed consent was obtained from each patient or (in the case of minors) their parents or guardians. The experimental protocols satisfied the national and international policies on ethical clearances established by the declaration of Helsinki of 1983.

DNA extraction Whole DNA extraction of clinical samples and reference strains was carried out according to the protocol previously described (Watts 2001) with the following modifications. Each sample was incubated in a water bath at $65^{\circ} \mathrm{C}$ for $1 \mathrm{~h}$, after which proteinase $\mathrm{K}$ $(500 \mu \mathrm{g} / \mathrm{mL})$ was added, and the mixture incubated at $55^{\circ} \mathrm{C}$ for a further $2 \mathrm{~h}$. Subsequently, $150 \mu \mathrm{L}$ of $\mathrm{NaCl} 6 \mathrm{M}$ were added, followed by centrifugation at $12,000 \mathrm{rpm}$ for $10 \mathrm{~min}$, transfer of the supernatant to a sterile vial and precipitation of the DNA with an equal volume of absolute ethanol at $-20^{\circ} \mathrm{C}$ overnight. Each sample was then centrifuged at $12,000 \mathrm{rpm}$ for $10 \mathrm{~min}$ at $4^{\circ} \mathrm{C}$, after which the supernatant was discarded and the precipitated material washed with $300 \mu \mathrm{L}$ of absolute ethanol and $200 \mu \mathrm{L}$ of
Table 1 Leishmania isolates and reference strains used in this study, showing species, origin, and GenBank accession numbers of the sequences of Cyt b gene

\begin{tabular}{llll}
\hline Species & Strain/isolate & Origin & GenBank accession number \\
\hline L. $($ L.) infantum & MHOM/FR/91/LEM2259 & France & EU499921 \\
L. $($ L. $)$ mexicana & MHOM/MX/95/NAN1 & Mexico & EU499922 \\
L. $(V$.$) braziliensis$ & MHOM/CO/88/UA301 & Colombia & EU499923 \\
L. $(V$.$) panamensis$ & MHOM/CO/87/UA140 & Colombia & EU499924 \\
L. $(V$.$) braziliensis$ & Lbrove1 & Ovejas/Sucre & EU499925 \\
L. $(V$.$) braziliensis$ & Lbrove2 & Ovejas/Sucre & EU499926 \\
L. $(V$.$) braziliensis$ & Lbrove3 & Ovejas/Sucre & EU499927 \\
L. $(V$.$) braziliensis$ & Lbrove4 & Ovejas/Sucre & EU499928 \\
L. $(V$.$) braziliensis$ & Lbrove5 & Ovejas/Sucre & EU499929 \\
L. $(V$.$) braziliensis$ & Lbrove6 & Ovejas/Sucre & EU499930 \\
L. $(V$.$) panamensis$ & Lpasam1 & Sampués/Sucre & EU499931 \\
L. $(V$.$) guyanensis$ & Lguove1 & Ovejas/Sucre & EU499932 \\
\hline
\end{tabular}




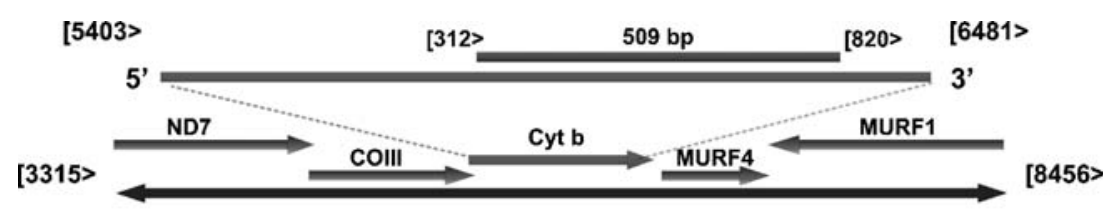

\section{Kinetoplastid Genome}

Fig. 2 Relative position of $C y t b$ gene and the 509 bp partial sequence in the kinetoplastid genome of Leishmania tarentolae

$70 \%$ ethanol. Finally, the DNA was resuspended in $100 \mu \mathrm{L}$ of high-purity water and stored at $4^{\circ} \mathrm{C}$ until used.

Amplification of the Cyt $b$ gene of Leishmania Polymerase chain reaction (PCR) was carried out using GoTaq Flexi DNA polymerase (Promega) as follows: initial denaturation at $94^{\circ} \mathrm{C}$ for $1 \mathrm{~min}$, followed by 35 amplification cycles at $94^{\circ} \mathrm{C}$ for $1 \mathrm{~min}, 50^{\circ} \mathrm{C}$ for $1 \mathrm{~min}$, and $72^{\circ} \mathrm{C}$ for $1 \mathrm{~min}$, with a final extension cycle at $75^{\circ} \mathrm{C}$ for $5 \mathrm{~min}$. Three microliters of whole DNA solution was used as a template. In order to amplify an $860 \mathrm{bp}$ fragment of the Leishmania Cyt b gene both LCBF1 (5'-GGT GTA GGT TTT AGT YTA GG-3') and LCBR2M (5'-ACA ATA AAC AAA TCA TAA TAT RCA ATT- $3^{\prime}$ ) primers were used. The LCBR2M primer is a modification of the original LCBR2 one (Luyo-Acero et al. 2004). PCR yields were visualized in $1.25 \%$ agarose gels.

Nucleotide sequencing and analyses Amplified products were purified by the ethanol-precipitation method. Nucleotide sequences from purified fragments were achieved by direct sequencing using the BigDye ${ }^{\mathrm{TM}}$ Terminator Cycling Kit in an ABI 3730xl DNA Analyzer. Sequences from both ends of double-stranded DNA were edited and assembled with molecular evolutionary genetic analysis (MEGA) version 4 software (Tamura et al. 2007). Nucleotide alignment was carried out with CLUSTAL W software (Higgins et al. 1994); nucleotide and aminoacidic composition and paired distances were calculated with MEGA 4. Location of the nucleotide sequences for the $C y t b$ gene of
Leishmania tarentolae was determined using basic local alignment search tool.

Sequences of isolates were compared to homologous sequences of Leishmania available in GenBank (access numbers AB095958, AB095959, AB095963, AB095967, AB095968, AB095969, EF579895, EF579900, EF579901, EF579905, and EF579915). Finally, evolutionary relationships between the obtained isolates and reference strains were inferred by means of a neighbor-joining algorithm (Saitou and Nei 1987).

\section{Results}

Eight clinical isolates were identified, obtained from patients from the region of Los Montes de María, Sucre. An 860 bp DNA fragment of the $C y t b$ gene was amplified in eight clinical isolates and four reference strains. These sequences were edited and 12509 bp sequences were obtained and submitted to GenBank with the accession numbers EU499921 to EU499932 (Table 1). The first and the last nucleotide positions of the $509 \mathrm{bp}$ DNA fragment of $C y t b$ gene of each tested isolate/strain corresponded to the 312 and 820 nucleotide of the $C y t b$ gene sequence of L. tarentolae (Fig. 2).

Six of these isolates were identified as $L$. (V.) braziliensis, one as $L$. ( $V$.) panamensis, and the other as $L$. $(V$.) guyanensis. All L. ( $V$.) braziliensis isolates and the one identified as $L$. $(V$.) guyanensis came from the rural area of
Fig. 3 Comparison of the nucleotide sequences of the $C y t b$ gene of Leishmania species included in this study. Nucleotide positions specific to the subgenera Viannia and Leishmania are marked with gray squares

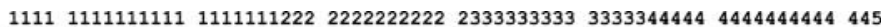
$\begin{array}{llllllllll}12355556 & 7788890011 & 1222222334 & 5677889011 & 1122223347 & 7011345677 & 7789912223 & 3345666778 & 990\end{array}$ $\begin{array}{rlllllllll}12355556 & 7788890011 & 1222222334 & 5677889011 & 1122223347 & 7011345677 & 7789912223 & 3345666778 & 990 \\ 3727312473 & 2812703814 & 7013678357 & 3578135836 & 7936891443 & 9923007946 & 8910610692 & 5813268179 & 587\end{array}$

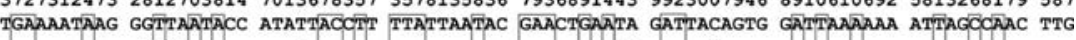

L. inf/PP75 L. inf/IPT1 L. inf/LEM235 L. inf/LEM2259 L. $\operatorname{mex} / \mathrm{M} 379$ L. mex/CRE47 L. $\operatorname{mex} / \mathrm{NAN} 1$

L.bra/INH -03 L.bra/LTB 300 L. bra/UA301 L.bra/Lbrove1 L. bra/Lbrove2 L.bra/Lbrove3 L.bra/Lbrove4 L. bra/Lbrove 5 L. bra/Lbrove6 L. pan/LEM702 L. pan/LS 94

L. pan/UA140

L. pan/Lpasam1 L. guy $/ M 4147$ L. guy/LEM85

L. guy/Lguove1

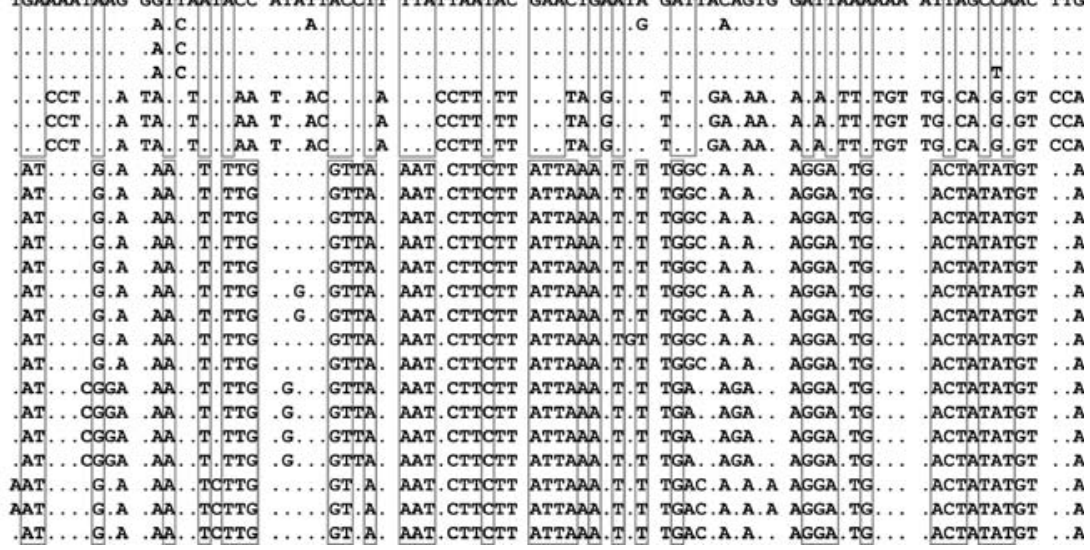


the municipality of Ovejas. The isolate identified as $L .(V)$ panamensis was from the municipality of Sampués. Alignment of the partial sequences of the $C y t b$ gene (Fig. 3) revealed that 83 nucleotide positions were polymorphic of which two were singletons and 81 informative under parsimony criteria. The interspecies pairwise distances (Table 2) reached a minimum value of 0.00589 among $L$. $(V$.$) guyanensis and L$. (V.) braziliensis and a maximum value of 0.11591 among $L$. (L.) mexicana and $L$. (V.) panamensis.

The interspecies variability of the clinical isolates identified as $L$. (V.) braziliensis was $0.39 \%$ due to nonsynonymous substitutions: $1 \mathrm{~A}-\mathrm{G}$ transition in the position 121 and $1 \mathrm{~T}-\mathrm{G}$ transversion in the position 244 over the 509 bp. Comparison of the partial sequence of the $C y t b$ gene of both clinical isolates and the reference strain showed that Lbrove1, Lbrove2, Lbrove3, Lbrove4, Lbrove5, and Lbrove6 exhibited a high degree of similarity (99.8-100\%) to the $\mathrm{MHOM} / \mathrm{CO} / 88 / \mathrm{UA} 301$ (GeneBank accession number EU499923), MHOM/EC/ 88/INH-03 (AB095967), and MHOM/BR/84/LTB300 (EF579900) L. (V.) braziliensis strain sequences. Lpasam1 showed a $100 \%$ similarity to the MHOM/CO/87/UA140 (EU499924), MHOM/PA/71/LS94 (AB095968), and MHOM/PA/71/LEM702 (EF579901) L. (V.) panamensis strain sequences.

Analysis of the clinical sequence Lguove1 and the MHOM/BR/75/M4147 (AB095969) and MHOM/GF/79/ LEM85 (EF579905) L. (V.) guyanensis strain sequences showed $99.6 \%$ similarity due to synonymous and nonsynonymous substitutions: $1 \mathrm{~A} / \mathrm{T}$ transversion on the third position and $1 \mathrm{~A} / \mathrm{G}$ transition on the position 376 . All the substitutions in the amino acid sequences of the $C y t b$ gene products were to amino acids of the same electric nature, which does not involve important alterations in the polypeptide structure. The neighbor-joining tree (Fig. 4) shows the clinical sequences clustered in defined groups of species, providing evidence for evolutionary associations among the clinical isolates and the reference strains.

\section{Discussion}

The similarity percentages and the phylogenetic tree obtained from the partial sequences of the $C y t b$ gene of Leishmania allowed us to distinguish clearly between $L$. $(V$.$) panamensis and L. (V.) guyanensis. Our results$ depart from those reported by Bañuls et al. (1999) who, using MLEE and random amplified polymorphic DNA (RAPD) data, questioned the distinctness between the two species $L$. $(V$.) panamensis and $L$. (V.) guyanensis. MLEE and RAPD data did not indicated that $L$. $(V$.) panamensis and $L$. $(V$.) guyanensis corresponded to distinct monophy-

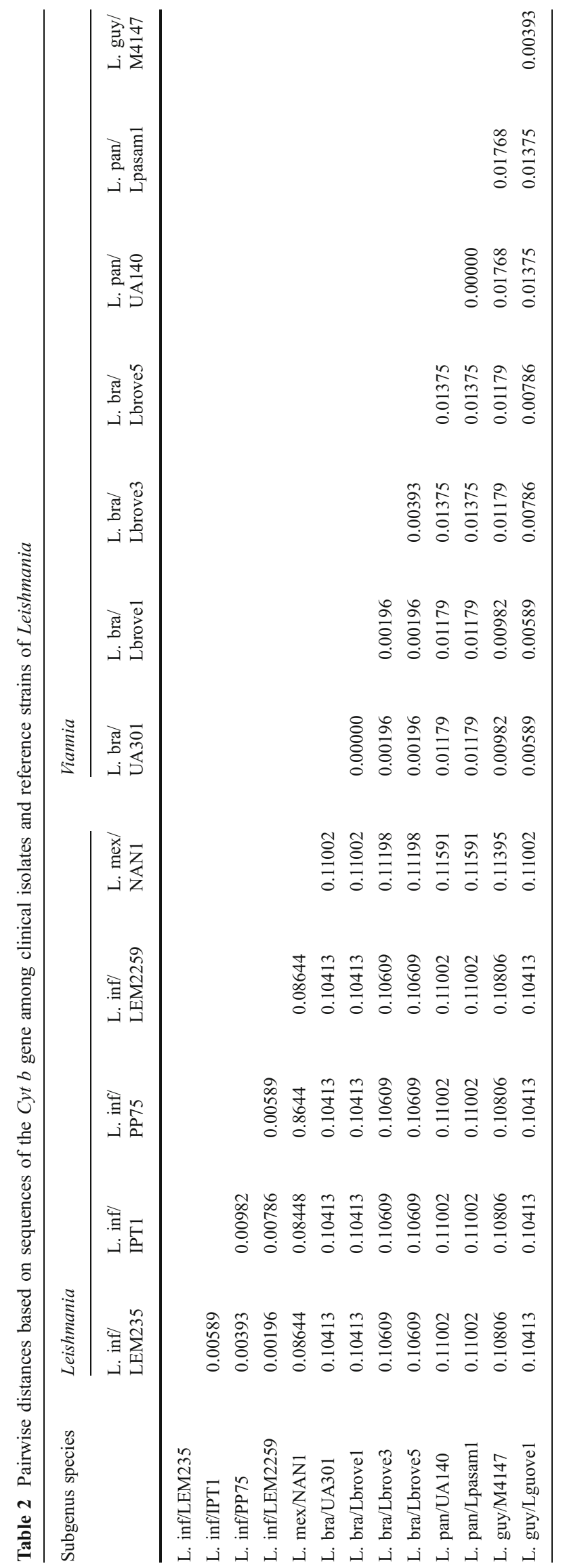


Fig. 4 Phylogenetic relationships of Leishmania species based on sequences of the $C y t b$ gene.

I L. (V.) braziliensis, II L. (V.) panamensis, III L. (V.) guyanensis, $I V L$. (L.) mexicana, $V$ L. (L.) infantum

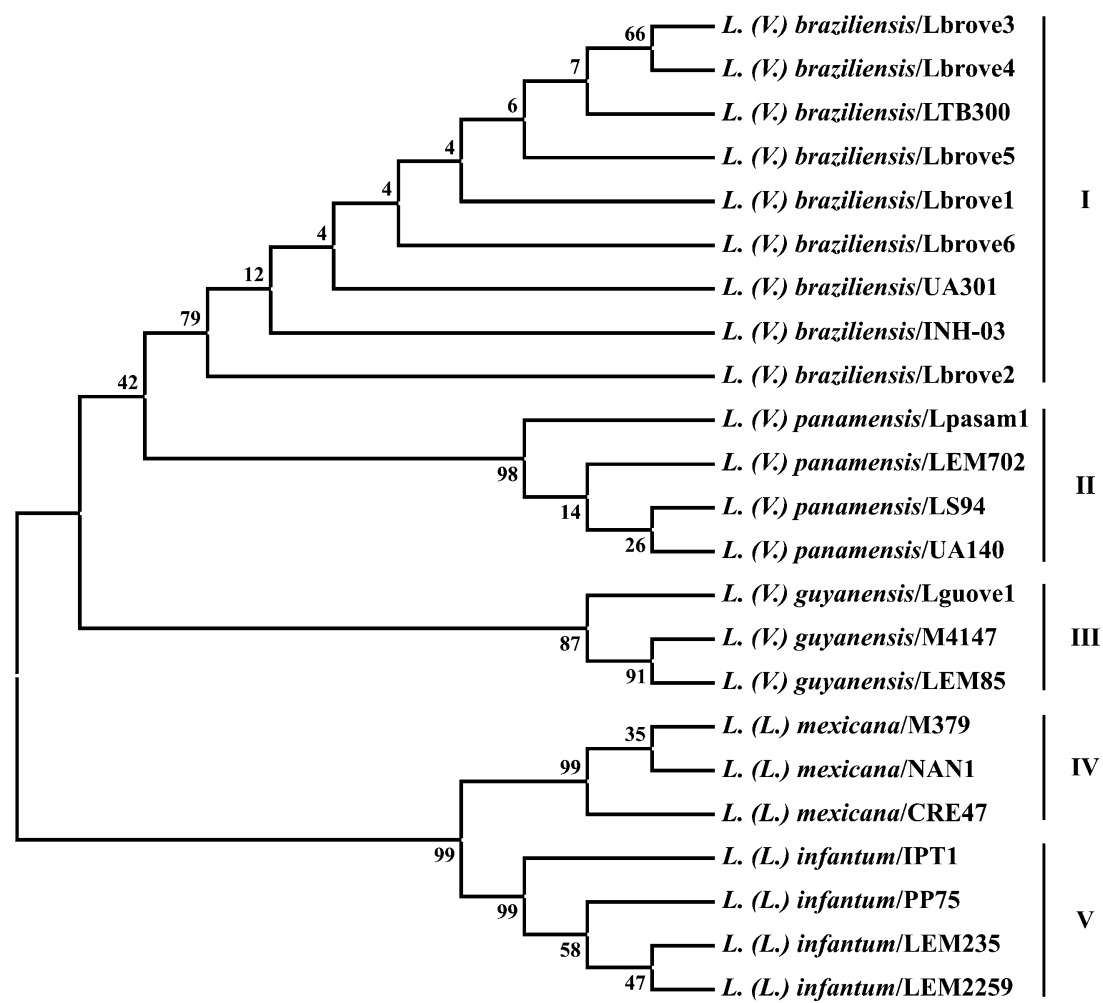

letic lines. However, the limited number of isolates evaluated in the present study makes it difficult to reach a final conclusion about the taxonomic status of these species. It would be necessary to increase the sample size in order to compare both studies.

The nucleotide sequence variation of the $C y t b$ gene, $509 \mathrm{bp}$ DNA fragment, allowed us to determine that $L$. $(V$. $)$ braziliensis, $L$. $(V$.) panamensis, and $L$. (V.) guyanensis are the probable etiological agents of CL in Sucre. This finding confirms previous reports of members of the $L$. (V.) braziliensis species complex being the causative agents of human leishmaniasis in this region (López 2000; Martínez et al. 2005). Analysis of the sequences allowed us to identify 33 and 26 nucleotide positions specific to the subgenera Viannia and Leishmania, respectively (Fig. 3).

Even more important was the detection of polymorphic sites that facilitated the discrimination of different Leishmania species within each subgenus. In the Viannia subgenus, combinations of bases were identified in positions 312 and 313 , which allowed us to distinguish the more epidemiologically relevant species: GC for $L$. (V.) braziliensis, AT for $L$. (V.) panamensis, and AC for $L$. (V.) guyanensis. Furthermore, our $C y t b$ gene sequences analyses showed 40 nucleotide positions key to the separation of $L$. (L.) infantum and $L$. (L.) mexicana species.

It is also important to highlight the higher numbers of nucleotide positions seen in members of the subgenus Leishmania (Leishmania) compared to those of Leishmania (Viannia), which is important in the identification of New
World Leishmania species. This can be explained by the relatively recent evolutionary separation among Viannia species, which has hindered the discrimination of these taxa by some laboratory techniques. Despite the low interspecies polymorphism of the Cyt $b$ gene, the key nucleotide positions described previously corroborate the potential of this gene as a molecular marker for Leishmania species characterization, not only in geographically related isolates, but also in widely separated regions.

From an epidemiological viewpoint, we surmise that the presence of $L$. $(V$. ) braziliensis in Sucre could be associated with the continuous reports of CL treatment failures with Glucantime $^{\circledR}$ and Miltefosine ${ }^{\circledR}$ in this area of the country. Limited effectiveness of the latter drug in the treatment of CL due to L. (V.) braziliensis has already been reported elsewhere (Soto et al. 2004). The presence of $L$. ( V.) panamensis in the municipality of Sampués can be linked to previous findings of this species in the neighboring departments of Córdoba (Saravia et al. 2002) and Antioquia (Ovalle et al. 2006), there being no strong geographical barriers that would impede the dispersion of its potential mammal reservoirs throughout the Caribbean coastal plain of Colombia.

The clinical isolate identified as $L$. (V.) guyanensis present in the locality of Canutalito (Ovejas municipality) is the first diagnosed case of CL due to $L$. ( $V$.) guyanensis not only in Sucre but anywhere on the Caribbean coast of Colombia. This is the second finding to suggest a possible expansion in the distribution of $L$. (V.) guyanensis beyond 
its natural focus around the Orinoco and Amazon rivers (Rodríguez-Barraquer et al. 2008). This observation suggests a possible change in the pattern of transmission of this species in Colombia, since Lutzomyia umbratilis, the proven sand fly vector of $L$. (V.) guyanensis, has not been reported from this region.

Acknowledgments We sincerely thank the clinicians of the health centers from Ovejas and Sampués municipalities for their support in the clinical sample collections, especially Mr. Calixto Galé (DASSSALUD). We also thank Dr. Iván Darío Vélez (PECET, Universidad de Antioquia) for providing the WHO reference strain. This study received financial support from DASSSALUD (Departamento Administrativo de Seguridad Social en Salud de Sucre) and the Universidad de Sucre. Experiments were carried out according to the Colombian current laws.

\section{References}

Bañuls AL, Jonquieres R, Guerrini F, Le Pont F, Barrera C, Espinel I, Guderian R, Echeverria R, Tibayrenc M (1999) Genetic Analysis of Leishmania Parasites in Ecuador: are Leishmania (Viannia) panamensis and Leishmania (V.) guyanensis Distinct Taxa? Am J Trop Med Hyg 61(5):838-845

Bañuls AL, Hide M, Prugnolle F (2007) Leishmania and the Leishmaniases: a parasite genetic update and advances in taxonomy, epidemiology and pathogenicity in humans. Adv Parasitol 64:1-109

Foulet F, Botterel F, Buffet P, Morizot G, Rivollet D, Deniau M, Pratlong F, Costa JM, Bretagne S (2007) Detection and identification of Leishmania species from clinical specimens by using a real-time PCR assay and sequencing of the Cytochrome $b$ gene. J Clin Microbiol 45:2110-2115

Herwaldt BL (1999) Leishmaniasis. Lancet 354:1191-1199

Higgins D, Thompson J, Gibson T (1994) CLUSTAL W: improving the sensitivity of progressive multiple sequence alignment through sequence weighting, position-specific gap penalties and weight matrix choice. Nucleic Acids Res 22:4673-4680

Kato H, Uezato H, Katakura K, Calvopiña M, Marco JD, Barroso PA, Gómez EA, Mimori T, Korenaga M, Iwata H, Nonaka S, Hashiguchi Y (2005) Detection and identification of Leishmania species within naturally infected sand flies in the Andean areas of Ecuador by a polymerase chain reaction. Am J Trop Med Hyg 72:87-93

López M (2000) Caracterización de Parásitos de un Foco mixto de Leishmaniasis en los Montes de María, Sucre, usando PCR y RAPD-PCR. Sincelejo. B.Sc. Thesis, Universidad de Sucre

Luyo-Acero GE, Uezato H, Oshiro M, Takei K, Kariya K, Katakura K, Gomez-Landires E, Hashiguchi Y, Nonaka S (2004) Sequence variation of the Cytochrome $b$ gene of various human infecting members of the genus Leishmania and their phylogeny. Parasitol 128:483-491

Marco JD, Bhutto AM, Soomro FR, Baloch JH, Barroso PA, Kato H, Uezato H, Katakura K, Korenaga M, Nonaka S, Hashiguchi Y (2006) Multilocus enzyme electrophoresis and Cytochrome $b$ gene sequencing-based identification of Leishmania isolates from different Foci of Cutaneous Leishmaniasis in Pakistan. Am J Trop Med Hyg 75:261-266

Martínez L, Assia Y, Rebollo J, Cochero S (2005) Evaluación de la técnica de PCR para la identificación de complejos de Leishmania a partir de biopsias de piel en el departamento de Sucre, Colombia. Biomédica 25:95

Ovalle CE, Porras L, Rey M, Rios M, Camargo YC (2006) Geographic distribution of Leishmania species isolated from patients at the National Institute of Dermatology Federico Lleras Acosta E.S.E., 1995-2005. Biomédica 26:145-151

Rioux JA, Lanotte G, Serres E, Pratlong F, Bastien P, Perieres J (1990) Taxonomy of Leishmania. Use of isoenzymes. Suggestions for a new classification. Ann Parasitol Hum Comp 65:111-125

Rodríguez N, Guzman B, Rodas A, Takiff H, Bloom B, Convit J (1994) Diagnosis of cutaneous Leishmaniasis and species discrimination of parasites by PCR and hybridization. J Clin Microbiol 32:2246-2252

Rodríguez-Barraquer I, Góngora R, Prager M, Pacheco R, Montero LM, Navas A, Ferro C, Miranda MC, Saravia NG (2008) Etiologic agent of an epidemic of cutaneous Leishmaniasis in Tolima, Colombia. Am J Trop Med Hyg 78:276-282

Saitou N, Nei M (1987) The neighbor-joining method: a new method for reconstructing phylogenetic trees. Mol Biol Evol 4:406-425

Saravia NG, Weigle K, Navas C, Segura I, Valderrama L, Valencia AZ, Escorcia B, McMahon-Pratt D (2002) Heterogeneity, geographic distribution, and pathogenicity of serodemes of Leishmania Viannia in Colombia. Am J Trop Med Hyg 66:738-744

Sierra D, Ochoa M, Calle JI, García G, Colorado D, Vélez ID (2006) Leishmania (Leishmania) mexicana en el corregimiento de San Matías, municipio de Gómez Plata, Antioquia, Colombia. Biomédica 26:232-235

Soto J, Arana BA, Toledo J, Rizzo N, Vega JC, Díaz A, Luz M, Gutiérrez $\mathrm{P}$, Arboleda $\mathrm{M}$, Berman JD, Junge $\mathrm{K}$, Engel J, Sindermann H (2004) Miltefosine for New World cutaneous Leishmaniasis. Clin Infect Dis 38:1266-1272

Tamura K, Dudley J, Nei M, Kumar S (2007) MEGA4: Molecular Evolutionary Genetics Analysis (MEGA) software version 4.0. Mol Biol Evol 24:1596-1599

Watts P (2001) Extraction of DNA from tissue: high salt method, Protocols for The Animal Genomics Laboratory [monograph on the Internet]. University of Liverpool, UK. School of Biological Sciences. Available in: http://www.genomics.liv.ac.uk/animal/ Protocol1.html. Accessed 12 Jan 2007

Zambrano P (2006) Informe de leishmaniasis, Colombia. Semanas 1 a 52 de 2005. Inf Quinc Epidemiol Nac 11:40-43 